\title{
Exploring the Rational Management and Control Model of Land Development Intensity in the Era of Big Data
}

\author{
Jing Luo * \\ Dianchi College, Yunnan University, Kunming. China \\ * reegine@qq.com
}

\begin{abstract}
The control of land development intensity is a prerequisite for urban construction and management, and rational intensity control is an inevitable demand and guarantee for urban scientific development. The study combines multi-source data information such as urban building information data, remote sensing aerial photography data, field survey data, urban planning data, questionnaire survey data, etc. On this basis, a Multi-dimensional model is established, and the development intensity model, technology, indicators, parameters, etc. are established. Explore and confirm. The article comprehensively considers the coordination between land potential and economic benefits, and environmental shaping, and conducts "value-based" control of the intensity of controlled planning and development. The results of the study show that the final land development intensity distribution of the Malong central urban area presents the highest land development intensity in the southwest and southeast of the old city. The final floor area ratio $F$ of the lot is in the range of 1.4-2.2, showing a declining trend from the main lot to the peripheral lot.
\end{abstract}

Keywords: Rational Management and Control; Big Data; Land Development Intensity; Multidimensional Value Orientation.

\section{Question Raised: The Dilemma of Land Development Intensity Control in the Transition Period}

With the continuous development of urbanization, the transformation of old cities and the construction of new districts are advancing rapidly in many cities in my country. In the process of urban reconstruction and construction, the low land development intensity leads to the rapid expansion of urban land and the serious waste of land resources; too high land development intensity will bring about adverse effects such as the decline of urban environmental quality. Whether it is predatory, extensive development or high-intensity, high-intensity development, it will affect the long-term sustainable development of the city.

Zhang Bo, Ge Yousong and Gu Mingdong [1] discussed the model in terms of social network and historical conditions such as commercial network planning and protection of historical style areas, and finally realized the rational development and utilization of land in the old city of Nanjing. The article emphasizes the influence of transportation factors on land development in the process of urban development, and analyzes the influence of transportation factors in depth through case comparison. However, the distribution of subway stations in the study selected the stations planned for layout by 2050. The analysis of factors affecting accessibility is too ideal. Other important factors other than transportation are not considered, such as infrastructure facilities, municipal facilities, and industrial facilities, The model has certain limitations. Yin Gui [2] combined with the macro-environment capacity control, combined with economic analysis of the determination of the development intensity index and the requirements of urban design to control the development intensity, and conducted an empirical study on the adjustment of the development intensity of the Litangba area in Shizhu County. However, the article focuses on the economic perspective, the market variable factors at the economic level have not been considered in detail, and the correction factors are only based on the overall density of the city, which is relatively one-sided and does not comprehensively consider other various environmental and social impacts in the process of urban development. factor. Huang Ruqin [3] carried out layer-by-layer progressive research on the development value "value-based" control method from the perspective of planning and preparation of the development volume prediction and allocation, the construction of the floor area ratio value domain form, and the linkage control between 
the development intensity indicators. In-depth analysis of existing problems to propose solutions and practical application in case cities to make the research on the development of "value-based" control in the control plan more feasible and scientific. However, there is no internal correlation model of tripartite indicators for the establishment of the development intensity of "valued localization" in the article.

This article changes from a pure engineering perspective to a research perspective, based on urban and rural planning, geographic information systems, urban economics, urban sociology and other disciplines, starting from the driving force behind urban land use, revealing the various factors that affect the intensity of urban development, establish factor systems and models that affect the intensity of urban development and conduct empirical research.

\section{Thinking and Exploring: The Multi-dimensional Value Orientation of Rational Management and Control}

\subsection{Logical Thinking on Rational Management and Control}

The research on the control of development intensity is an important part of the detailed control planning in urban planning and management. This paper takes urban big data, GIS basic data information database, and RS (remote sensing) data as the data foundation to build a research framework of urban development intensity and carry out research. The research investigated a wide range of data and carried out data analysis and storage, such as the number, nature, name, new and old, structure of buildings in the central urban area stored in GIS files, urban commercial, transportation, education, medical, cultural, sports, green space, historical monuments, Landmark buildings, in addition to the use of remote sensing aerial data files in the central city, etc., laid the foundation for a more comprehensive understanding and understanding of the study area.

\subsection{Method Model of Rational Control}

The study evaluates the urban development intensity from multiple dimensions, and summarizes its motivations as the driving mechanism of urban land potential value, economic benefits, and urban features, and serves as the logical main line, premise, and basis for the evaluation of development intensity.

According to the logic of "model construction-factor recognition-measurement evaluation", the research establishes the efficiency model and the revision model from the efficiency dimension, economic dimension and environmental dimension, and obtains the land of the Malong central urban area in the dynamic role and feedback of the model Reasonable range of unit floor area ratio index.

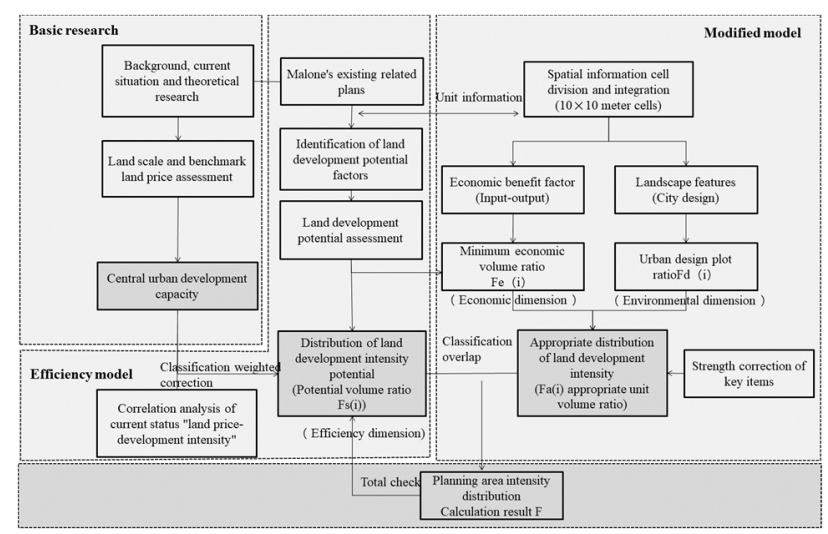

Fig 1. Technology Roadmap 


\section{Empirical Research: Rational Management and Control Model of Land Development Intensity in Malong}

\subsection{Research Objects and Data Foundation}

(1) Research object

The scope of this study is the planned construction land area of the central urban area in the Malong city master plan, with an area of about 40 square kilometers. The research object is the urban construction land within the research scope.

(2) Status survey and information storage

The research integrates multi-source data information such as urban building information data, remote sensing aerial photography data, field survey data, urban planning data, questionnaire survey data and so on. In the processing of urban building information data, the study area is divided into grids, and the $10 \times 10 \mathrm{~m}$ cell grid is used as the minimum evaluation unit to grid process and manage the urban area. By converting the building status information such as the number, nature, name, old and new, structure, historical monuments, and landmarks of urban buildings into GIS data information, and entering it into a geographic database, a huge spatial information database is established.

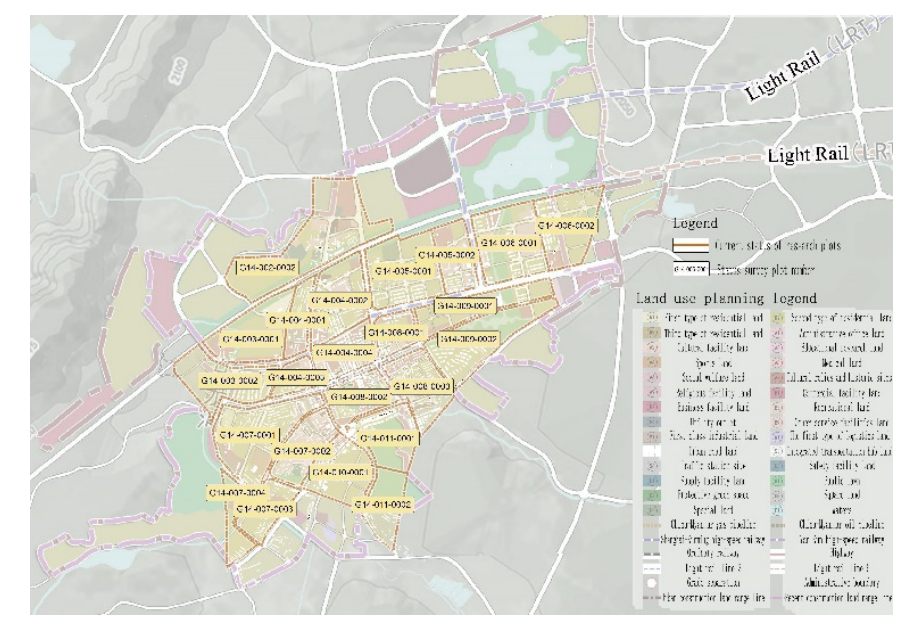

Fig 2. Schematic diagram of the status survey and information survey

The study used the GIS software Arc GIS to establish a spatial database to organize, store, and analyze massive spatial data, including (1) grid division of parcel information (cells of about $10 \times 10 \mathrm{~m}$ ), (2) Malong City The current building information is entered into the database, (3) The format conversion and database entry of basic data such as transportation, commerce, and public service facilities are performed.

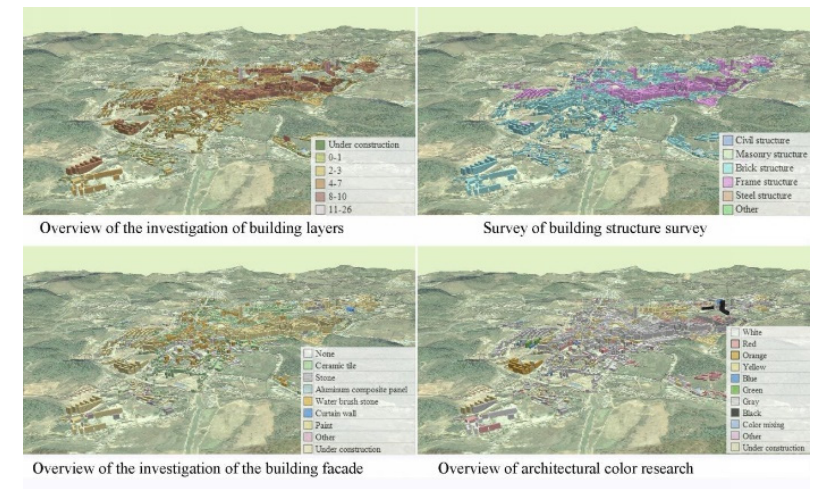

Fig 3. Schematic diagram of the number of layers, structure, facade and color of buildings in the center of Malone 


\subsection{Efficiency Model--Measurement of Potential Development Intensity Fs(i)}

Efficiency model: measurement of the land's own development potential

Evaluate the land development and construction potential within the scope of the study based on the Malong city master plan, and establish an evaluation index system using the main factors that affect the land development potential (land value). The indicator system is divided into three levels: first-level indicators, second-level indicators, and third-level indicators, that is, the basic element layer, the derived factor layer, and the factor layer, which mainly include five main factors (commercial agglomeration, traffic accessibility, social service facilities The degree of perfection, the quality of the landscape, the inferiority of natural conditions). Calculate the score of the analysis unit $(10 \mathrm{~m} \times 10 \mathrm{~m})$ covering the whole area, that is, the score of land development potential.

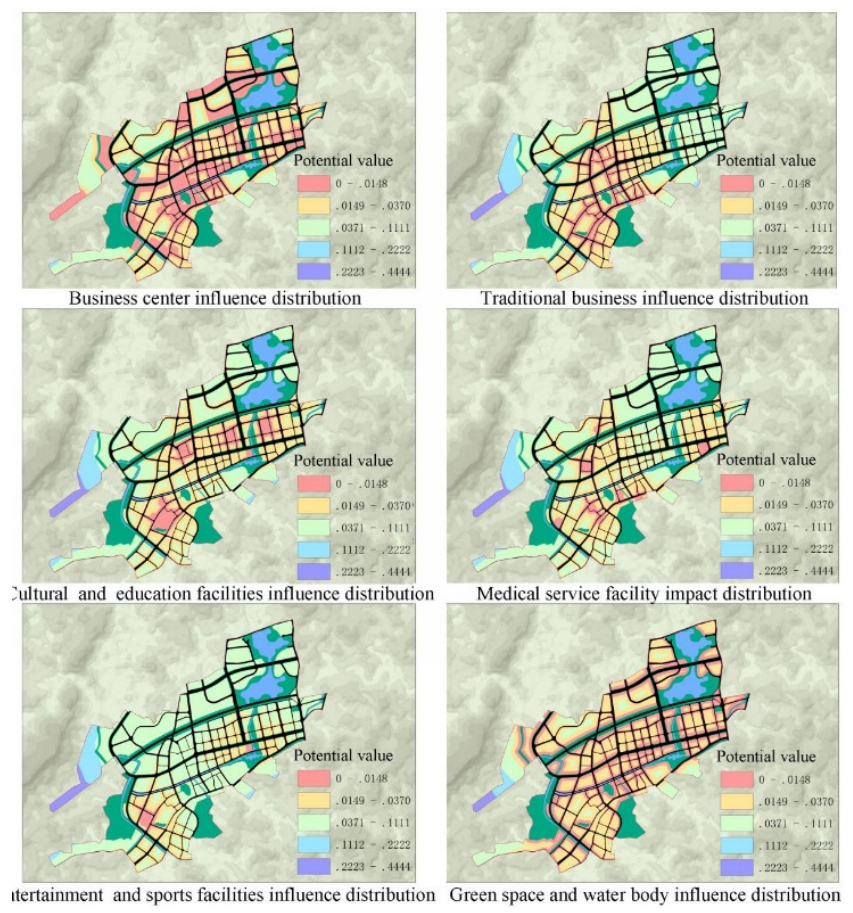

Fig 4. Distribution map of land potential value under the influence of single factor

According to the efficiency model, the land potential value analysis under the single factor influence, the potential floor area ratio $\mathrm{Fa}(\mathrm{i})$ distribution of the Malong central city is shown in the following figure. From the figure, it can be seen that the potential in the central and southern parts of the central city and the east section of the east-west main road The analysis value of the floor area ratio $\mathrm{Fa}(\mathrm{i})$ is the highest, the potential floor area ratio $\mathrm{Fa}(\mathrm{i})$ of the land along the two main roads of east, west, north and south is generally higher, and the potential floor area ratio $\mathrm{Fa}(\mathrm{i})$ of the northwest corner and southeast corner is lower.

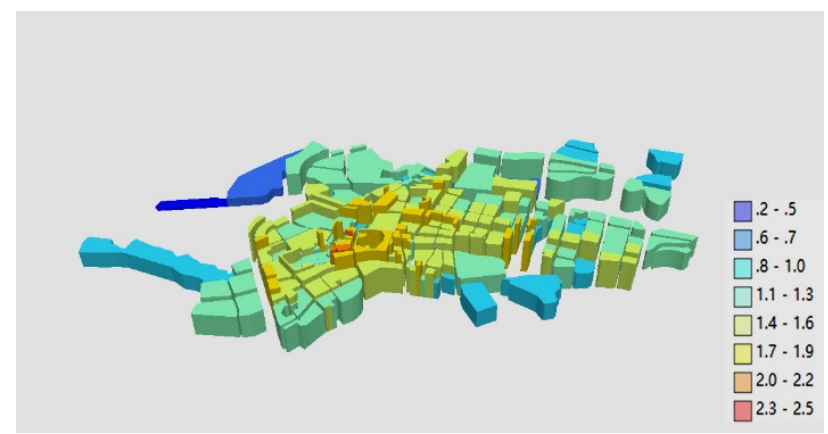

Fig 5. Spatial distribution of land development potential value under efficiency model 


\subsection{Modified Model-suitable for Developing Strength Measures}

The revised model takes the application of economic market rules and the shaping of urban design space form as the starting point, and calculates the minimum economic floor area ratio $\mathrm{Fa}$ (i).

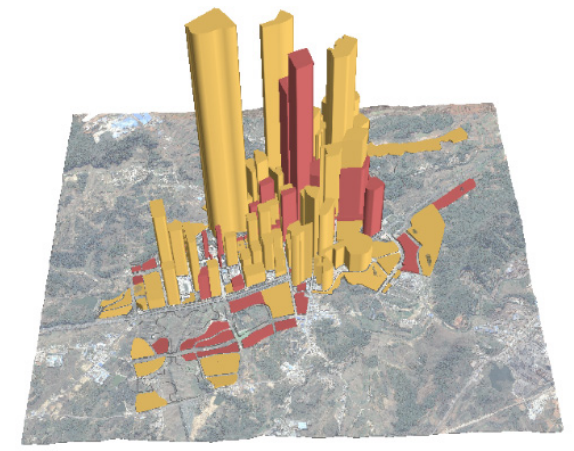

Fig 6. Distribution map of land demolition during the planning period

Calculate the minimum economic floor area ratio Fe(i) by analyzing the input and output of the old urban land at a predetermined land price level.

Table 1. The table of various expenses and quantitative interpretation under the economic inputoutput method

\begin{tabular}{|c|c|c|c|}
\hline \multicolumn{2}{|c|}{ Input-output cost } & \multicolumn{2}{|c|}{ Quantitative interpretation } \\
\hline \multirow{10}{*}{$\begin{array}{c}\text { Economic } \\
\text { investment }\end{array}$} & $\begin{array}{l}\text { Land transfer fees and } \\
\text { related fees }\end{array}$ & \multicolumn{2}{|c|}{$\begin{array}{l}\text { (1) The current average transaction price of } \\
\text { residential land is } 450,000 \text { yuan } / \mathrm{mu} \\
\text { (2) The average transaction price of commercial } \\
\text { land is } 400,000 \text { yuan } / \mathrm{mu}\end{array}$} \\
\hline & $\begin{array}{l}\text { Major municipal } \\
\text { development costs }\end{array}$ & \multicolumn{2}{|c|}{$\begin{array}{l}\text { (1) } 150,000 \text { yuan } / \mathrm{mu} \\
\text { (2) Residential, commercial, public construction } \\
120 \text {, industrial, warehousing } 90 \text { yuan / square } \\
\text { meter }\end{array}$} \\
\hline & $\begin{array}{c}\text { Building demolition } \\
\text { fees, land compensation } \\
\text { fees, resettlement } \\
\text { subsidies }\end{array}$ & \multicolumn{2}{|c|}{$\begin{array}{l}\text { (1) Old city reconstruction } 1 \text { square meter } \\
\text { compensation } 0.7 \text { square meter new building } \\
\text { (2) Requisitioned land averages } 80,000 \text { yuan per } \\
\text { mu }\end{array}$} \\
\hline & $\begin{array}{l}\text { Surveying and } \\
\text { designing costs }\end{array}$ & \multicolumn{2}{|l|}{1.2 million yuan $/ \mathrm{km} 2$} \\
\hline & \multirow{3}{*}{$\begin{array}{l}\text { Construction and } \\
\text { installation costs }\end{array}$} & Low-rise building & 750 yuan $/ \mathrm{km} 2$ \\
\hline & & Mid-rise building & 850 yuan $/ \mathrm{km} 2$ \\
\hline & & High-rise building & 1200 yuan $/ \mathrm{km} 2$ \\
\hline & Community fees & \multicolumn{2}{|c|}{250 yuan $/ \mathrm{km} 2$} \\
\hline & $\begin{array}{l}\text { Outdoor greening } \\
\text { engineering fees, } \\
\text { building exterior } \\
\text { decoration, taxes, etc. }\end{array}$ & \multicolumn{2}{|c|}{ 350yuan $/ \mathrm{km} 2$} \\
\hline & $\begin{array}{c}\text { Other taxes, unforeseen } \\
\text { fees }\end{array}$ & \multicolumn{2}{|c|}{$15 \%$} \\
\hline \multirow{3}{*}{$\begin{array}{l}\text { Economic } \\
\text { output }\end{array}$} & Residential land & \multicolumn{2}{|c|}{ 3400yuan $/ \mathrm{km} 2$} \\
\hline & Commercial land & \multicolumn{2}{|c|}{8800 yuan $/ \mathrm{km} 2$} \\
\hline & Gross profit margin & \multicolumn{2}{|c|}{$25 \%$} \\
\hline
\end{tabular}

In the comparison of the real estate development cost of the old urban area and the minimum economic floor area ratio $\mathrm{Fe}(\mathrm{i})$ of land development, the relationship between the development cost of each block unit in the central district of Malong and the minimum economic floor area ratio Fe(i) is:

$$
\frac{\left[P_{1} \times A+P_{2} \times A \times F_{\mathrm{e}}+B \times P_{3}+D \times A+\left(P_{4}+P_{5}+P_{6}+P_{7}\right) \times A \times F_{\mathrm{e}}\right] \times(1+\mathrm{r})}{A \times F_{\mathrm{e}}}
$$

$>s$

(1) A-Plot area; $B$-Current building area; $S$-Unit sales unit price; $r$-Gross profit margin;

(2) $P_{1}$-Unit price of land transfer; $P_{2}$-Major municipal development costs; $P_{3}$-Unit price of demolition and resettlement compensation; $D$-Surveying and designing costs; $P_{4}$-Construction and 
installation cost unit price; $P_{5}$-Community fees; $P_{6}$-Outdoor greening engineering fees, building exterior decoration, taxes, etc.; $P_{7}$-Other taxes, unforeseen fees;

Converted Fe (i):

$$
F_{\mathrm{e}}<\left\{\left[\mathrm{s}-\frac{\left(P_{2} \times A+\left(P_{4}+P_{5}+P_{6}+P_{7}\right) \times A\right) \times(1+\mathrm{r})}{A}\right] \times A\right\}
$$

On this basis, on the one hand, the urban design plot ratio Fd(i) of the plot is determined according to the relevant human settlement environment factors and the current urban planning; on the other hand, economic viability is taken as the priority principle, and the following comparison principles and methods The floor area ratio Fe(i) and the urban design floor area ratio Fd(i) compare and judge the two intensity indicators to generate the unit intensity value range.
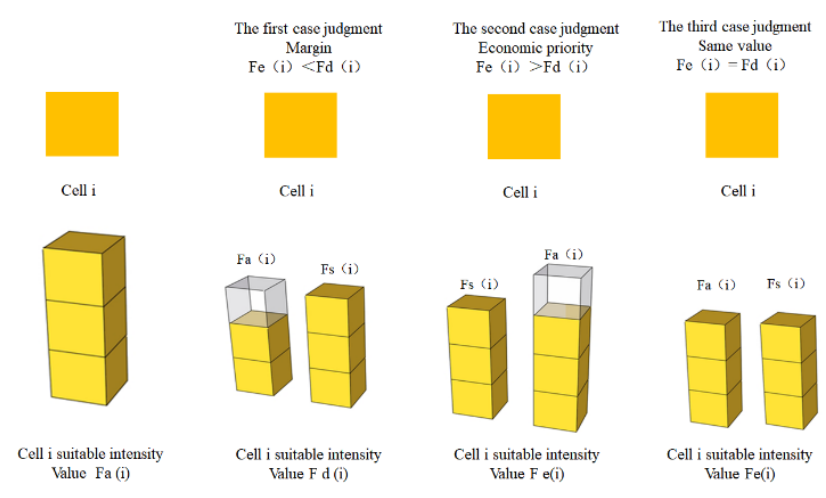

Cell i

Fig 7. Value plot of suitable floor area ratio (Liu Zhongyu, Luo Jing, A preliminary study on urban land development intensity)

Through the analysis of the development characteristics of Malong City, starting from the economic dimension and environmental dimension, based on the economic perspective, the development intensity distribution of the old urban area is obtained, and the index is revised in conjunction with the urban design of the project area, and the appropriate floor area ratio of land development $\mathrm{Fa}$ (i). It can be seen from the measurement of the revised model and revised indicators that the areas with high land development intensity in Malong City are the southwest and southeast areas of the existing old city, and the areas with low development intensity are basically the typical areas in urban planning, such as the surrounding areas of Longhu Wait.

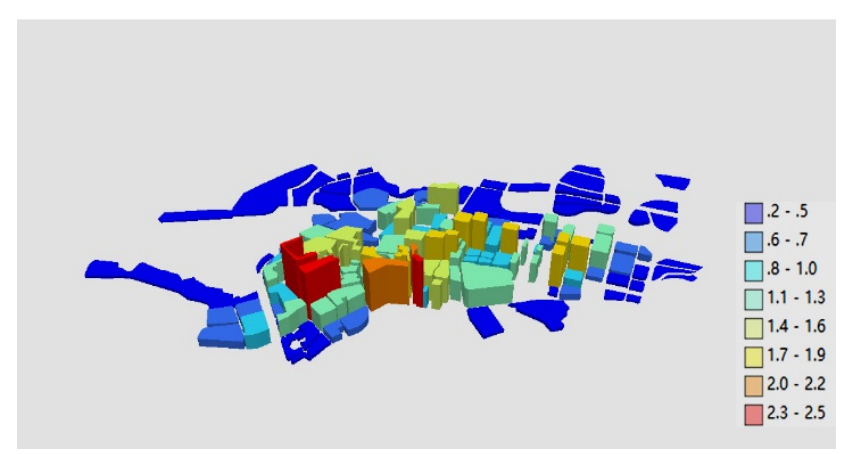

Fig 8. Corrected floor area ratio Fs(i)

\subsection{Conclusion and Discussion}

According to the calculation rules, the spatial calculation is performed on the three-dimensional model results to generate the intensity distribution model of the central urban area and the intensity 
model of classification land use. Through this project, the quantitative analysis and research on the construction intensity of the old city reconstruction and the development of the new district will be conducted to provide a more intuitive strength recommendation conclusion for urban land development.

It can be seen from the figure that, combined with the measurement of three different dimensions of land potential, economic benefit, and human settlement environment, the land development intensity distribution of the Malong downtown area presents the highest land development intensity in the southwest and southeast of the old city, followed by land along the east-west main road in other parts of the old city, the periphery of the main road is the next secondary distribution pattern. The final vacancy rate $\mathrm{F}$ of most of the land is in the range of 1.4-2.2, showing a declining trend from the main land to the outer land.

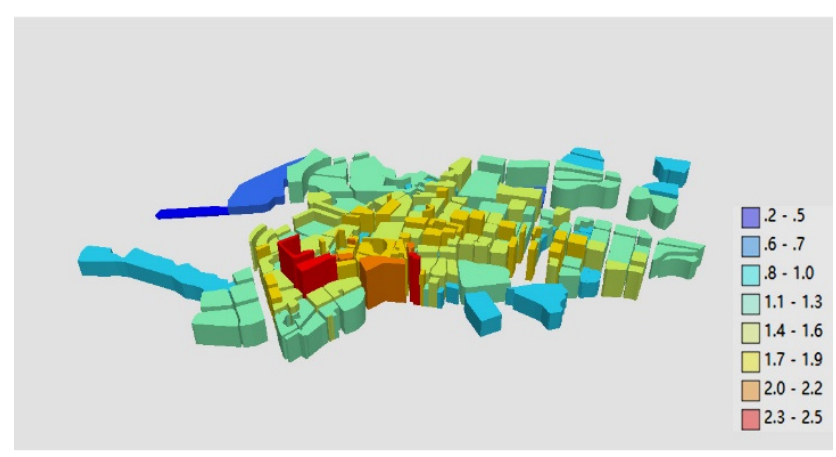

Fig 9. Final floor area ratio $\mathrm{F}$

This research is an attempt on Multi-dimensional quantitative calculation of urban development intensity. According to the logical idea of "model construction-factor recognition-measurement evaluation", the efficiency model and the economic model are established from the efficiency dimension, the economic dimension, and the environmental dimension. In the dynamic role and feedback of the three models, the "value-based" control of the land development intensity is carried out. It is necessary and practical to determine the development intensity index systematically and scientifically, improve the integrity and foresight of urban development and construction, increase the authority and scientific of urban planning, and provide relatively scientific method guidance.

\section{Acknowledgments}

Yunnan Provincial Department of Education Research Fund Granted (Item Number: 2018JS739), Research on Development Strength Control of Malong County Central District Based on Multidimensional Modeling of Big Data.

\section{References}

[1] Zhang Bo, Ge Yousong, Gu Mingdong. Study on the intensity of land development in urban central area- Taking the old city of Nanjing as an example, J. Journal of Hebei Normal University (Natural Science Edition), 2010,03:359-364.

[2] Yin Gui. Research on the intensity control of urban old district development based on economic perspective, D. Chongqing University, 2010.

[3] Huang Yuqin. Research on "indentation" of development intensity in controlled detailed planning, D. Xi'an University of Architecture and Technology, 2011.

[4] Zhou Liya, Zou Bing. Discussion on the technical method of multi-level control of urban density--The main idea of "Shenzhen Special Economic Zone Density Zoning Study", J. Urban Planning, 2004, 12: 2832. 